Published in final edited form as:

J Behav Med. 2011 December ; 34(6): 519-530. doi:10.1007/s10865-011-9333-9.

\title{
Types of prayer and depressive symptoms among cancer patients: the mediating role of rumination and social support
}

\author{
John E. Pérez, \\ Department of Psychology, University of San Francisco, 2130 Fulton Street, San Francisco, CA \\ 94117, USA
}

Amy Rex Smith,

Department of Nursing, University of Massachusetts Boston, Boston, MA, USA

Rebecca L. Norris,

Department of Psychology, University of Massachusetts Boston, Boston, MA, USA

Katia M. Canenguez,

Department of Psychology, University of Massachusetts Boston, Boston, MA, USA

Elizabeth F. Tracey, and

Hospice Care of Southwestern Connecticut, Stamford, CT, USA

Dana-Farber Cancer Institute, Boston, MA, USA

Susan B. DeCristofaro

Dana-Farber Cancer Institute, Boston, MA, USA

John E. Pérez: jperez6@usfca.edu

\section{Abstract}

We examined the association between different types of prayer and depressive symptoms-with rumination and social support as potential mediators-in a sample of predominantly White, Christian, and female ambulatory cancer patients. In a cross-sectional design, 179 adult cancer outpatients completed measures of prayer, rumination, social support, depressive symptoms, and demographic variables. Type and stage of cancer were collected from electronic medical charts. Depressive symptoms were negatively correlated with adoration prayer $(r=-.15)$, reception prayer $(r=-.17)$, thanksgiving prayer $(r=-.29)$, and prayer for the well-being of others $(r=-$. $26)$. In the path analysis, rumination fully mediated the link between thanksgiving prayer and depressive symptoms ( $\beta$ for indirect effect $=-.05$ ), whereas social support partially mediated the link between prayer for others and depressive symptoms ( $\beta$ for indirect effect $=-.05$ ). These findings suggest that unique mechanisms may link different prayer types to lower depressive symptoms among cancer patients.

(C) Springer Science+Business Media, LLC 2011

Correspondence to: John E. Pérez, jperez6@usfca.edu. 


\section{Keywords}

Religion; Spirituality; Prayer; Coping; Depression; Rumination; Social support; Cancer

\section{Introduction}

Many cancer patients struggle with depression-a condition associated with notably poor health outcomes. In a literature review of psychological and psychiatric problems among cancer patients, depression was the most likely psychological problem to persist throughout the course of the illness (van't Spijker et al., 1997). Furthermore, a recent meta-analysis demonstrated that mortality rates are $25 \%$ higher in cancer patients experiencing depressive symptoms and up to $39 \%$ higher in cancer patients diagnosed with major or minor depression (Satin et al., 2009). Thus, it is important to identify and understand coping methods, such as prayer, that may decrease levels of depressive symptoms among cancer patients.

The link between religious variables and depressive symptoms in the general population is well established (Smith et al., 2003). In particular, several types of prayer have been associated with lower levels of distress and greater well-being in non-patient populations (Ladd \& Spilka, 2002, 2006; McCullough \& Larson, 1999). Among cancer patients, prayer is a widely used coping mechanism (Levine et al., 2009; Ross et al., 2008); however, little is known about how different types of prayer impact their health and well-being. A few qualitative studies suggest that different types of prayer are associated with well-being among cancer patients (e.g., Gall \& Cornblat, 2002; Levine et al., 2009); however, it is possible that some types of prayer may exacerbate distress throughout the course of cancer illness (Taylor et al., 1999). Prayer is a complex, multidimensional behavior; there is no dominant theoretical model or consistent approach to measuring prayer types (Masters \& Spielmans, 2007). Prevailing models are based on both theological and scientific conceptual frameworks; however, comparisons across studies are difficult because of multiple taxonomies and problems with construct validity (e.g., presumably unidimensional prayer subscales contain multiple attitudes, beliefs, and behaviors) (see Ladd \& Spilka, 2002).

\section{Taxonomies of prayer and their associations with well-being}

Foster (1992) categorized prayer under three general dimensions: inward prayers (seeking self-transformation), upward prayers (seeking intimacy with the divine), and outward prayers (seeking connections with others). Each of these broad categories includes seven specific types of prayer for a total of 21 prayer types. Ladd and Spilka $(2002,2006)$ applied Foster's theoretical framework to the development and validation of eight prayer types: examination, tears (inward); sacramental, rest (upward); and radical, suffering, intercession, petition (outward). Although based on Western, Christian conceptions of prayer, Foster's model provides a helpful framework for empirical study of prayer types within various religions. Moreover, this tridirectional understanding of prayer-with inward, upward, and outward movements - provides a foundation for examining health-related mechanisms, both intrapersonal (cognitive) and interpersonal (social). 
Several other scholars have identified various types of prayer that may be linked to health and well-being (Breslin \& Lewis, 2008; Laird et al., 2004; McCullough \& Larson, 1999; Meraviglia, 2002; Poloma \& Pendleton, 1989, 1991). For example, Poloma and Pendleton $(1989,1991)$ identified four types of prayer through factor analysis of fifteen items from the Akron Area Survey: colloquial (e.g., thanking God, asking God for guidance), petitionary (e.g., asking God for things for oneself or others), ritual (e.g., reading from a book of prayers), and meditative (e.g., worshiping and adoring God, reflecting on the Bible). Laird et al. (2004) developed a multidimensional inventory of prayer that includes five types of prayer: adoration (focus on worship and praise of God), confession (acknowledging faults, misdeeds, or shortcomings), reception (passively waiting for divine wisdom, understanding, or guidance), supplication (requests for God's intervention in specific life events for oneself or others), and thanksgiving (expressing gratitude for life circumstances).

Specific to cancer, qualitative studies on prayer and cancer provide descriptions of prayer in natural settings, unencumbered by preset categories. In a mixed method study of prayer among breast cancer survivors, Levine et al. (2009) identified prayers for petitioning, comfort, and praise. In another qualitative study of religious coping among breast cancer survivors, Gall and Cornblat (2002) categorized their findings into two types of prayer: personal and intercessory. Personal prayer was divided into petitionary, requesting inner strength and courage, and colloquial, most frequently offering thanksgiving to God. Intercessory prayer was described as others offering prayer for the cancer patient, and was linked to the social support provided by the church community.

In studies among non-cancer samples, various types of prayer have different associations with measures of well-being. In a cross-sectional, community-based study controlling for demographic variables and other prayer variables, colloquial prayer was associated with greater happiness, meditative prayer was associated with greater existential well-being, and ritual prayer was associated with higher levels of negative affect; however, petitionary prayer was not associated with any of the well-being measures (Poloma \& Pendleton, 1989). In a cross-sectional study of online participants, three types of prayer (adoration, thanksgiving, and reception) were positively correlated with multiple well-being measures, whereas confession was negatively correlated with multiple well-being measures (Whittington \& Sher, 2010). In a short-term longitudinal study of middle-aged and older patients receiving open-heart surgery, petitionary prayer predicted better postoperative wellbeing, whereas conversational (colloquial) prayer was associated with greater postoperative distress (Ai et al., 2008). Taken together, these studies suggest that different types of prayer have different associations with well-being in different samples. Next, we focus on prayer for others (outward) and thanksgiving prayer (upward) because of their theoretical and empirical links to rumination, social support, and well-being.

\section{Prayer for others and thanksgiving prayer}

While much attention has been paid to the impact of intercessory prayer on the health outcomes of the people who are the object of prayer (Masters \& Spielmans, 2007; Masters et al., 2006), less attention has been paid to the health impact of praying for others on the prayer (the person who offers the prayer). Nonetheless, a few studies suggest that there may be 
some health benefits from praying for others - an outward form of prayer focused on strengthening human-to-human connections (Foster, 1992; Ladd \& Spilka, 2002). In an experimental study, more frequent prayer for others predicted greater increases in selfesteem and greater decreases in negative affect (i.e., state and trait anxiety, depressive symptoms, multidimensional measure of negative affect) for the pray-er (O'Laoire, 1997).

In a sample of medically ill older adults, participants who engaged in more religious helping experienced fewer depressive symptoms (Koenig et al., 1998). However, in addition to praying for the well-being of others, the measure of religious helping included offering spiritual strength or help to family, friends, or others. Therefore, it is not clear whether praying for others specifically was associated with fewer depressive symptoms. In a nationwide survey of older adults, there was an interaction between financial strain and praying for others on self-rated health (Krause, 2003). That is, the negative association between financial strain and health was reduced significantly for older adults who prayed for others very often. Other studies suggest that prayer for others cultivates positive attributes such as gratitude and forgiveness (Lambert et al., 2009, 2010), which are linked to wellbeing (Emmons \& McCullough, 2003; McCullough, 2000). Taken together, these studies suggest that praying for others may promote well-being in the pray-er.

Thanksgiving prayer is an expression of gratefulness for life circumstances directed towards God or a power outside of oneself. In Foster's (1992) theoretical framework, thanksgiving is an upward form of prayer, centering on the human-divine relationship. Gall and Cornblat (2002) described that their sample of breast cancer survivors were thankful for "not just being alive, but for ... available treatments, family, friends, nature and other life joys" (p. 528). While there have been no quantitative studies that specifically assessed thanksgiving prayer in cancer patients, there is an obvious theoretical link to the gratitude literature. In a recent review, Wood et al. (2010) found a strong association between gratitude and multiple measures of well-being. Moreover, studies have found that gratitude is positively associated with spirituality and religiousness (Emmons \& Kneezel, 2005; McCullough et al., 2002; Watkins et al., 2003). Thus, we expect that thanksgiving prayer will be linked to well-being among religious and spiritual cancer patients.

\section{Potential mediators: rumination and social support}

The cognitive mechanisms that link prayer to the well-being of the pray-er have rarely been examined. Understanding the mechanisms that link between religious variables and wellbeing has important implications for developing potential psychosocial interventions in various populations (Ai et al., 2007, 2008; Pérez et al., 2009a, b). One potential mechanism may be reduced self-focused attention. A large body of research has linked self-focused attention to negative affect (Mor \& Winquist 2002). Rumination is a unique type of selffocus that is strongly related to depressive symptoms (Nolen-Hoeksema, 1991). Response style theory (Nolen-Hoeksema, 1991; Nolen-Hoeksema et al., 2008) posits that ruminative responses prolong the duration of depressive symptoms because they allow depressed mood to negatively bias thinking and interfere with instrumental behavior and problem-solving. There is sound empirical evidence to support these basic tenets of response style theory (Mor \& Winquist, 2002; Nolen-Hoeksema, 1991; Nolen-Hoeksema et al., 2008; Rood et al., 2009). 
Prayer for others (outward) and thanksgiving prayer (upward) may promote well-being by reducing the level of ruminative self-focused attention, shifting focus away from one's negative affect. There is evidence that other behaviors that focus on the well-being of others, such as religious volunteerism and offering religious social support, enhance subjective health and well-being (Borgonovi, 2008; Krause, 2009; Norris et al., 2009). Thanksgiving prayer may also reduce rumination by focusing one's gratitude toward God or a higher power. Researchers have clearly identified a link between gratitude and well-being, but they have not yet uncovered the mechanisms of that link (see Wood et al., 2010 for a review).

Interpersonal factors may also mediate the link between prayer and depressive symptoms. There is a large body of research indicating that perceived social support is a key mechanism linking religious beliefs and practices to well-being (Howsepian \& Merluzzi, 2009; Koenig et al., 2001; Strawbridge et al., 1997). A growing body of research also suggests that prayer specifically is linked to well-being via higher levels of perceived social support from both human (Ai et al., 2009; Krause et al., 2000) and divine sources (Ai et al., 2005; Ladd \& McIntosh, 2008). In particular, prayer for the well-being of others may facilitate deep human to human interconnectedness (Ai et al., 2009), which can lead to a sense of well-being for the pray-er.

\section{The present study}

Because of the widespread use of prayer among cancer patients (e.g., Ross et al., 2002), it is important to understand its effect on well-being among cancer patients. It is also important to understand the underlying mechanisms in the link between prayer and well-being. Much of the literature on prayer and health consists of positive correlations between measures of well-being and a single-item measure of the frequency of prayer, without much attention to the way in which people pray (see Masters \& Spielmans, 2007; McCullough \& Larson, 1999 for reviews). Guided by the tridirectional theoretical framework of prayer types (Foster, 1992; Ladd \& Spilka, 2002, 2006) and response style theory (Nolen-Hoeksema, 1991), the current study builds on previous work that has examined the association between different types of prayer and well-being. Using Laird et al.'s (2004) taxonomy of prayer types, we examined the association between depressive symptoms and five general types of prayeradoration, confession, reception, supplication, and thanksgiving. In addition, we examined the association between depressive symptoms and three specific types of petitionary prayer in the context of cancer-prayer for one's physical health, prayer for emotional strength, and prayer for others' well-being. Distinguishing between different foci of petitionary prayer is important because the content of one's prayer requests may have different associations with well-being (Krause, 2003). Of particular importance, we examined two potential mediators -rumination and social support-in the link between prayer types and depressive symptoms.

\section{Hypotheses}

First, we hypothesized that prayer for the well-being of others would be associated with lower depressive symptoms compared to self-focused prayer (e.g., prayer for improvement of one's own health or emotional strength). Second, we hypothesized that thanksgiving prayer would be associated with lower depressive symptoms. Third, we hypothesized that 
lower levels of rumination and higher levels of social support would mediate the relationship between these prayer types and lower depressive symptoms. Finally, we explored the association between depressive symptoms and the following general types of prayer: adoration, confession, reception, and supplication.

\section{Method}

\section{Participants}

Participants were 179 adult cancer outpatients at three northeastern US hospital cancer centers. Patients with stage II-stage IV cancers, as well as advanced cancers that may have not been staged (e.g., hematological malignancies), were eligible for the study. Patients had to be 18 years or older, be able to read English, and be in active outpatient treatment (e.g., radiation, chemotherapy, palliative care). We excluded patients with stage I cancers and/or those who were not in active treatment because we expected that early cancer stage and nontreatment status would have a significantly different impact on depressive symptoms (Weisman \& Worden, 1976-1977). Based on the exclusion criteria, 42 patients who contacted the study team were not eligible to participate. Participants were predominantly White, Christian, and female with an average of 16 years of education. Demographic characteristics of the sample are presented in Table 1.

\section{Measures}

Demographic questionnaire-The demographic questionnaire included age, gender, racial/ethnic self-identification, religious affiliation, marital status, work status, years of education, and family income.

Medical chart review-Type and stage of cancer were collected from electronic medical charts.

Multidimensional prayer inventory (MPI) (Laird et al., 2004)—The 20-item MPI assesses the frequency of daily and weekly prayer, duration of typical prayers, perceived efficacy of prayer (faith), and five distinct types of prayer. For the current study, we included the five types of prayer in the analyses. In addition, six items specific to cancerrelated prayer were added to the MPI for the present study: two items assessed the degree to which respondents prayed for emotional strength from God, two items assessed the degree to which respondents prayed for healing, and two items assessed the degree to which respondents prayed for the well-being of others (see Table 2). For all types of prayer, participants responded on a 7-point scale ranging from 1 (never) to 7 (all the time), indicating the frequency that they used each type of prayer during the past month. In the current study, Cronbach's alpha coefficient ranged from .86 to .92 for the five general types of prayer and from .89 to .96 for the cancer-related prayer scales (see Table 2).

UCLA measure of social support (Schwarzer et al., 1994)—This instrument assesses the frequency and quality of social support pertaining to a particular domain (e.g., living with cancer). It measures two dimensions using a total of 24 items. One dimension assesses the types of social support (information and advice, instrumental assistance, 
encouragement and reassurance, and listening and understanding). Another dimension assesses the source of social support (family, partner, friends, and group domains). Items assessing the frequency of social support use a 5-point Likert-type scale ranging from 1 (never) to 5 (very often) (e.g., "How often did each of these people listen to and try to understand your concerns about your cancer-related stress?"). Items assessing the quality of social support use a 7-point Likert-type scale, ranging from 1 (very dissatisfied) to 7 (very satisfied) (e.g., "How satisfied or dissatisfied have you been with the listening and understanding you have received concerning your feelings about your cancer-related stress?"). In the current study, we used the total perceived frequency of social support received from all sources. Because several participants did not report social support in the partner domain, we used the mean item score in the analyses. Cronbach's alpha of this measure in the current study was .89 .

Ruminative responses scale-revised (RRS-R) (Treynor et al., 2003)—The RRS-R is a 10-item scale of responses to depressed mood that include two components, Reflective Pondering (e.g., "I analyze recent events to try to understand why I am depressed") and Brooding (e.g., "I think, what I am doing to deserve this?"). Item response options range from 1 (never) to 4 (always). In the current study, we used the Brooding scale because it more specifically represented the negative cognitions associated with rumination. Cronbach's alpha for the Brooding scale in this study was .71.

\section{Center for epidemiological studies-depression scale (CES-D) (Radloff, 1977)—} The CES-D is a 20-item measure that assesses cognitive, affective, and vegetative symptoms of depression and has been used frequently in community settings. Using the previous week as a time frame, participants respond on scale ranging from 0 (rarely or none of the time) to 3 (most of the time) to statements such as "I felt depressed." To control for possible confounds between cancer-related symptoms and somatic symptoms of depression, we excluded the five somatic complaints from the computation of the CES-D (i.e., fatigue, poor appetite, lack of energy, restless sleep, and poor concentration). The remaining 15 cognitive and affective items were summed with four items reverse-scored to calculate a composite (range 0-45) used as a measure of depressive symptoms. The CES-D has demonstrated good reliability and validity among cancer patients (Hann et al., 1999). Cronbach's alpha for the CES-D, excluding the somatic symptoms, was .88 in the present study.

\section{Procedure}

This study was approved by the Institutional Review Boards at the Dana-Farber Cancer Institute and the University of Massachusetts Boston. Data were collected from 2008 to 2009. Patients were recruited into the study from three hospitals by three methods: (1) brochures providing a brief overview and purpose of the study, eligibility criteria, and study team contact information were distributed in the waiting areas of the hospital cancer centers; (2) an introductory letter, signed by the primary oncologists, was mailed out or given to identified patients informing them of this study by a member of their healthcare team; (3) previously screened, eligible outpatients were approached by a member of the study staff after being introduced to the patient by a member of their healthcare team. 
Participants provided consent to participate in the study, including having their medical charts reviewed to obtain relevant diagnostic staging of cancer and other health information. Patients who met eligibility criteria and were interested in participating were mailed two copies of the consent form and the study questionnaire along with a self-addressed, stamped envelope. Participants were asked to return the completed consent form and questionnaire within 1 week. If the questionnaire was not received after 2 weeks, a study staff member followed up by phone, mail, or e-mail, based on the participants' preferred method of correspondence. Participants received a $\$ 25$ gift card as compensation for their participation.

\section{Data analysis}

Data were screened using Predictive Analytics Software (PASW) Statistics 18.0 to determine whether the variables met the assumptions of normality and linearity for path analysis. Based on examination of $z$-scores and histograms, two outliers were found for the rumination variable. These scores were changed to a value one unit larger than the next most extreme score in the distribution (Tabachnick \& Fidell, 2007). Subsequently, all variables met the assumptions of normality and linearity. Based on Cook's distance, there were no multivariate outliers among the predictor variables (Fox, 1991). Because there were less than 5\% missing data among the variables and the data were missing at random, missing data were estimated using an expectation maximization method (Tabachnick \& Fidell, 2007). The following variables were examined as potential covariates in the model: age, gender, race/ethnicity, education level, family income, time since diagnosis, and cancer stage. Of these, age $(r=-.20, p<.001)$ and family income $(r=-.19, p<.05)$ were significantly associated with the dependent variable, depressive symptoms. Age was also associated with rumination $(r=-.31, p<.001)$. Therefore, these variables were included as covariates in the model. The lack of a significant association between cancer stage and depressive symptoms was likely due to the exclusion of stage I cancer patients from the sample, which restricted the variability of this measure.

To examine the relationship among prayer types, rumination, and depressive symptoms, the data were analyzed using path analysis in the LISREL 8.71 program (Jöreskog \& Sörbom, 1996). The path analysis began with the hypothesized model. $T$-values of each parameter were then examined to determine if certain paths could be dropped from the model in order to develop a more parsimonious model. Because of the relatively small sample size for path analysis, we used one-tailed significance tests $(p<.05)$ for the estimated parameters where we had directional hypotheses (Jöreskog \& Sörbom, 1996). In addition, modification indices were examined to determine if any fixed paths needed to be estimated. In the model fitting procedure, we changed one parameter at a time. Chi-square $\left(\chi^{2}\right)$ change, Root Mean Square Error of Approximation (RMSEA), and Comparative Fit Index (CFI) were then used to determine if the re-estimated model fit the data (Jöreskog \& Sörbom, 1996). To avoid multicollinearity problems, we selected two types of prayer of the most theoretical interest and the strongest empirical support—prayer for others and thanksgiving prayer-for the path analysis. 


\section{Results}

Pearson correlation coefficients were run to determine which prayer types were associated with depressive symptoms (see Table 3 ). Depressive symptoms were negatively associated with prayer for others $(r=-.26, p<.001)$, thanksgiving $(r=-.29, p<.001)$, adoration $(r=$ $-.15, p<.05)$, and reception $(r=-.17, p<.05)$. Correlations, means, and standard deviations of the variables in the two models are presented in Table 4.

\section{The hypothesized model}

Figure 1 shows the hypothesized path model. According to the model, higher levels of prayer for others and thanksgiving prayer predict lower levels of depressive symptoms. The relationship between these prayer types and depressive symptoms is mediated by rumination and social support. That is, higher levels of prayer for others and thanksgiving prayer lead to lower levels of rumination, which in turn positively predicts depressive symptoms. Higher levels of these prayer types also lead to higher levels of social support, which in turn negatively predicts depressive symptoms. Age and family income are included as covariates for depressive symptoms.

\section{Model estimation}

The hypothesized model did not fit the data adequately, $\chi^{2}(7, N=179)=38.41, p<.001$, RMSEA $=.15, \mathrm{CFI}=.85$. Based on $t$-tests, three non-significant parameters were fixed: age $\rightarrow$ depressive symptoms, prayer for others $\rightarrow$ rumination, and thanksgiving prayer $\rightarrow$ social support. Based on modification indices (MI), two paths were estimated: first, prayer for others $\rightarrow$ depressive symptoms $(\mathrm{MI}=11.25)$, then age $\rightarrow$ rumination $(\mathrm{MI}=14.27)$. The final model fit the data very well, $\chi^{2}(8, N=179)=16.21, p=.04$, RMSEA $=.07, \mathrm{CFI}=.96$. The overall model explained $32 \%$ of the variance in depressive symptoms. Significant standardized parameter coefficients for the final model are presented in Fig. 2.

\section{Direct effects}

More prayer for others directly predicted lower levels of depressive symptoms $(\beta=-.22, p$ $<.001)$. More prayer for others also predicted higher levels of social support $(\beta=.30, p<$. 001). In turn, greater social support predicted lower levels of depressive symptoms $(\beta=-$. $15, p<.05)$. More thanksgiving prayer predicted lower levels of rumination $(\beta=-.12, p<$. $05)$. In turn, greater rumination predicted higher levels of depressive symptoms $(\beta=.40, p$ $<.001)$. Among the covariates, older age predicted lower levels of rumination $(\beta=-.29, p$ $<.001)$ and higher family income predicted lower levels of depressive symptoms $(\beta=-.18$, $p<.01)$.

\section{Indirect effects}

The inverse relationship between prayer for others and depressive symptoms was partially mediated by higher levels of social support ( $\beta$ for indirect effect $=-.05, p<.05$ ). The inverse relationship between thanksgiving prayer and depressive symptoms was fully mediated by lower levels of rumination $(\beta$ for indirect effect $=-.05, p<.05)$. Finally, the inverse relationship between older age and depressive symptoms was mediated by rumination $(\beta$ for indirect effect $=-.12, p<.001)$. 


\section{Discussion}

In this study, prayers of adoration, reception, thanksgiving, and prayers for the well-being of others were significantly associated with lower levels of depressive symptoms in cancer patients. Controlling for age and family income level, rumination mediated the relationship between thanksgiving prayer and depressive symptoms. In addition, social support mediated the relationship between prayer for others and depressive symptoms. Contrary to our hypotheses, rumination did not mediate the relationship between prayer for the well-being of others and depressive symptoms; nor did social support mediate the relationship between thanksgiving prayer and depressive symptoms. These findings suggest that there may be unique mechanisms between different prayer types and well-being.

In terms of direct associations between prayer types and depressive symptoms, other studies have found similar results. Greater frequency of prayer for the well-being of others was significantly associated with lower levels of depressive symptoms in older adults (Krause, 2003), medically ill older adults (Koenig et al., 1998), and in healthy adult volunteers (O'Laoire, 1997). In addition, both reception prayer and thanksgiving prayer were associated with well-being in an internet-based convenience sample of healthy participants (Whittington \& Sher, 2010). Reception and thanksgiving prayer were also associated with subjective well-being in a sample of patients with osteoarthritis (Laird et al., 2004). Moreover, reception prayer, also referred to as contemplative or meditative prayer, has been associated with well-being in community samples (McCullough \& Larson, 1999; Poloma \& Pendleton, 1989, 1991). Little research has been conducted on adoration prayer; it was not associated with well-being among patients with either rheumatoid arthritis or osteoarthritis (Laird et al., 2004), but was associated with lower depressive symptoms in our sample. In addition to thanksgiving prayer, both adoration and reception can be conceptualized as upward forms of prayer, connecting the pray-er to the divine.

Some types of prayer were not associated with depressive symptoms in our sample of cancer patients. As with adoration, little research has been conducted on confession and well-being. Confession—an inward prayer emphasizing self-examination—was linked to higher levels of distress in a non-clinical, web-based sample (Whittington \& Sher, 2010), but was not associated with depressive symptoms in our clinical sample. Supplication (petition)_requests for God's intervention in specific life events for oneself or others-has shown positive, negative, and null associations with well-being in various samples (McCullough \& Larson, 1999). Supplication was unrelated to depressive symptoms in our sample, perhaps because of the lack of specificity about both the request and the focus of the request (self versus others). Finally, specific types of self-focused prayer-prayer for one's own health and prayer for one's own emotional strength — were not associated with depressive symptoms. Based on response style theory, one might predict that prayer for one's health could be associated with greater distress, particularly among cancer patients with lower levels of intrinsic spirituality. However, it appears that the outward and upward forms of prayer had the strongest associations with well-being in our sample of cancer patients.

A unique contribution of this study is the examination of potential mechanisms linking specific types of prayer to depressive symptoms among cancer patients. Results suggest that 
depressive symptoms may be reduced for people who offer prayers of thanksgiving by decreasing ruminative self-focused attention. Cancer patients who focus on what they are thankful for in life may spend less time ruminating over their illness, which may lead to lower levels of depressive symptoms. Furthermore, it is possible that the people with cancer who focus on what they are thankful for may experience an increase in positive emotions, which may lead to lower levels of rumination and depressive symptoms.

Folkman and Moskowitz (2000) posited that positive emotions can co-occur with stress and serve as a buffer against depression. It is possible that thanksgiving prayer cultivates specific positive emotions by providing a reminder of blessings in life. This coping strategy may be beneficial as a buffer against depression for cancer patients who are dealing with chronic stressors related to their diagnosis, treatment, and severity of symptoms. To date, few studies have examined the relationship between prayer, gratitude, and well-being; however, higher levels of gratitude have been associated with positive affect and well-being in studies of healthy people (Emmons \& McCullough, 2003; Wood et al., 2009) and psychotherapy outpatients (Toussaint \& Friedman, 2009). Of note, one experimental study found a causal relationship between higher prayer frequency and gratitude among undergraduate students (Lambert et al., 2009). It would be useful for future studies to examine positive affect as a potential mechanism in the association between thanksgiving prayer and lower depressive symptoms.

Results from this study indicate that prayer for the well-being of others was related to lower levels of depressive symptoms, but not because cancer patients were ruminating less.

Nonetheless, this relationship was partially mediated by social support. Thus, cancer patients who pray for others may experience less negative affect because they perceive greater social support. Although we did not ask about the person or people who were the focus of the prayers from cancer patients, qualitative research suggests that cancer patients often pray for the well-being of family and friends, including their loved ones' comfort during and after the respondent's life with cancer (Levine et al., 2009; Taylor \& Outlaw, 2002). Cancer patients may also be praying for other people who are struggling with cancer. Thus, praying for the well-being of others may foster a deep interconnectedness with others (Ai et al., 2009; Masters \& Spielmans, 2007) who are collectively impacted by cancer illness.

Because a direct association remained between prayer for others and depressive symptoms, this suggests that this link is likely mediated by additional factors. A study of undergraduate students found that students who prayed for the well-being of a friend also demonstrated increases in selfless concern-a variable that mediated the link between prayer for others and forgiveness (Lambert et al., 2010). Similarly, it is possible that praying for others may increase levels of selfless concern in cancer patients, which may reduce depressive symptoms. In addition, prayer for the well-being for others may also be similar to thanksgiving prayer in that it may function as a benefit-reminding technique. Praying for the well-being of other people who are also suffering may help cancer patients remember all of the things they have in life for which they are grateful. Finally, our measure of self-focused attention assessed rumination about one's negative mood, that is, brooding about the symptoms of depression themselves. It is likely that a measure of rumination about cancer symptoms and consequences of the illness would be a more salient mechanism between 
prayer for others and negative affect in this population. Future studies, including the development of a measure assessing rumination about cancer, are needed to investigate these relationships further.

We suggest that future studies on specific prayer types and well-being include potential mechanisms such as gratitude, positive affect, selfless concern, and social connectedness. In clinical samples, decreased rumination about their specific illness would also be a salient mechanism to study. In addition, researchers could investigate potential biological pathways that might explain the relationship between different types of prayer and well-being. Although several biological studies have been conducted on meditation and health (Seeman et al., 2003), little is known about such pathways between different types of prayer and health outcomes.

There were some limitations to the study that should be addressed in future studies. Participants in this study were a non-random, clinical sample of predominantly White, female, well-educated, Christian cancer patients. Consequently, it is difficult to generalize the results of this study to populations that differ by race, gender, socioeconomic status, and religious affiliation. Moreover, it is possible that more spiritually-oriented people were attracted to this study and that the complete range of cancer patients using various types of prayer was not well represented. In addition, conclusions that can be drawn from this study are limited due to the cross-sectional design. Reverse causality or other unidentified and unmeasured variables might explain the study findings. For example, dispositional variables such as optimism may greatly influence an individual's desire to offer prayers of thanksgiving or pray for the well-being of others. Experimental studies are warranted in order to determine if the relationship between type of prayer and well-being is causal. Finally, path modeling as a data analytic tool has its own limitations. Our analyses can only demonstrate whether the hypothesized models fit the data well; alternative models may also fit the data well.

Despite these limitations, few studies have examined the association between specific prayer types and depressive symptoms, or potential mechanisms that may facilitate the relationship between these variables among cancer patients. The present study provides support for an association between specific types of prayer and the well-being of the pray-er with advanced cancer. Of most interest, we found that lower rumination was a unique mediator between thanksgiving prayer and lower depressive symptoms, whereas greater social support was a unique mediator between prayer for others and lower depressive symptoms. Consequently, we suggest that these potential mechanisms be explored in future prospective and experimental studies on the relationship between prayer types and well-being among cancer patients and patients with other chronic illnesses.

If specific types of prayer reduce or protect against depressive symptoms, spiritual cancer patients may benefit from pastoral counseling that helps to cultivate prayers for others, thanksgiving prayer, and other prayer types that enhance well-being. For example, cancer patients who self-blame or view cancer as a punishment from God or a higher power could be encouraged by chaplains and other spiritual counselors to use prayers that are positively associated with well-being. This is especially important for patients with advanced cancer 
who suffer from the burden of depression because depression appears to be associated with a worse prognosis and increased mortality (Evans et al., 2005; Onitilo et al., 2006; Satin et al., 2009). However, we caution that further experimental research is needed to establish a causal link between prayer types and well-being. Furthermore, the cultivation of specific prayer types must be culturally and theologically congruent with patients' faith.

The field of religion/spirituality and health has grown dramatically in the past few decades. As the field develops, there is a greater need to understand mechanisms linking specific dimensions of religiousness and well-being. Prayer is a widely used, yet understudied, coping mechanism among cancer patients and other populations with chronic illnesses. As Pargament (2002) argued, because of the complexity of religion, we need to ask a more refined and difficult question, "How helpful or harmful are particular forms of religious expression for particular people dealing with particular situations in particular social contexts according to particular criteria of helpfulness or harmfulness?" (p. 168). Examining both the positive and negative pathways linking specific types of prayer to well-being in clinical populations is an important step in that direction.

\section{Acknowledgments}

This study was funded by a National Cancer Institute U56 Comprehensive Cancer Partnership Program Grant (U56 CA118635). We gratefully acknowledge the contributions of Sarah Ahmad, Esteban Barreto, Laurel Radwin, Geraldine Sanon, Max Stewart, and the participants in this research. We especially thank Karen Emmons and Adan Colon-Carmona for their support and skillful leadership of the DF/HCC-UMass Boston U56 collaboration.

\section{References}

Ai AL, Corley CS, Peterson C, Huang B, Tice TN. Private prayer and quality of life in cardiac patients: Pathways of cognitive coping and social support. Social Work in Health Care. 2009a; 48:471-494.10.1080/00981380802589829 [PubMed: 19396714]

Ai AL, Park CL, Huang B, Rodgers W, Tice TN. Psychosocial mediation of religious coping styles: A study of short-term psychological distress following cardiac surgery. Personality and Social Psychology Bulletin. 2007; 33:867-882.10.1177/0146167207301008 [PubMed: 17483394]

Ai AL, Tice TN, Huang B, Rodgers W, Bolling SF. Types of prayer, optimism, and well-being of middle-aged and older patients undergoing open-heart surgery. Mental Health, Religion \& Culture. 2008; 11:131-150.10.1080/13674670701324798

Ai, AL.; Tice, TN.; Kelsey, CL. Coping after 9/11: Deep interconnectedness and struggle in posttraumatic stress and growth. In: Morgan, M., editor. The impact of 9/11 on psychology and education: The day that changed everything?. New York: Palgrave MacMillan; 2009b. p. 115-138.

Ai AL, Tice TN, Peterson C, Huang B. Prayers, spiritual support, and positive attitudes in coping with the September 11 national crisis. Journal of Personality. 2005; 73:763-791.10.1111/j. 1467-6494.2005.00328.x [PubMed: 15854013]

Borgonovi F. Doing well by doing good: The relationship between formal volunteering and selfreported health and happiness. Social Science and Medicine. 2008; 66:2321-2334.10.1016/ j.socscimed.2008.01.011 [PubMed: 18321629]

Breslin MJ, Lewis CA. Theoretical models of the nature of prayer and health: A review. Mental Health, Religion and Culture. 2008; 11:9-21.10.1080/13674670701491449

Emmons RA, Kneezel TT. Giving thanks: Spiritual and religious correlates of gratitude. Journal of Psychology and Christianity. 2005; 24:140-148.

Emmons RA, McCullough ME. Counting blessings versus burdens: An experimental investigation of gratitude and subjective well-being in daily life. Journal of Personality and Social Psychology. 2003; 84:377-389.10.1037/0022-3514.84.2.377 [PubMed: 12585811] 
Evans DL, Charney DS, Lewis L, Golden RN, Gorman JM, Krishnan KRR, et al. Mood disorders in the medically ill: Scientific review and recommendations. Biological Psychiatry. 2005; 58:175189.10.1016/j.biopsych.2005.05.001 [PubMed: 16084838]

Folkman S, Moskowitz JT. Positive affect and the other side of coping. American Psychologist. 2000; 55:647-654.10.1037/0003-066X.55.6.647 [PubMed: 10892207]

Foster, R. Prayer: Finding the heart's true home. New York: Harper Collins; 1992.

Fox, J. Regression diagnostics. Newbury Park, CA: Sage Publications; 1991.

Gall TL, Cornblat MW. Breast cancer survivors give voice: A qualitative analysis of spiritual factors in long-term adjustment. Psycho-Oncology. 2002; 11:524-535.10.1002/pon.613 [PubMed: 12476434]

Hann D, Winter K, Jacobsen P. Measurement of depressive symptoms in cancer patients: Evaluation of the Center for Epidemiological Studies Depression Scale (CES-D). Journal of Psychosomatic Research. 1999; 46:437-443.10.1016/S0022-3999(99)00004-5 [PubMed: 10404478]

Howsepian BA, Merluzzi TV. Religious beliefs, social support, self-efficacy and adjustment to cancer. Psycho-Oncology. 2009; 18:1069-1079.10.1002/pon.1442 [PubMed: 19189320]

Jöreskog, K.; Sörbom, D. LISREL 8: User's reference guide. Chicago, IL: Scientific Software International; 1996.

Koenig, HG.; McCullough, ME.; Larson, DB. Handbook of religion and health. New York: Oxford University Press; 2001.

Koenig HG, Pargament KI, Nielsen J. Religious coping and health status in medically ill hospitalized older adults. Journal of Nervous and Mental Disease. 1998; 186:513521.10.1097/00005053-199809000-00001 [PubMed: 9741556]

Krause N. Praying for others, financial strain, and physical health status in late life. Journal for the Scientific Study of Religion. 2003; 42:377-391.10.1111/1468-5906.00189

Krause N. Church-based volunteering, providing informal support at church, and self-rated health in late life. Journal of Aging and Health. 2009; 21:63-84.10.1177/0898264308328638 [PubMed: 19144969]

Krause N, Chatters LM, Meltzer T, Morgan DL. Using focus groups to explore the nature of focus groups in late life. Journal of Aging Studies. 2000; 14:191-212.10.1016/S0890-4065(00)80011-0

Ladd KL, McIntosh DN. Meaning, God, and prayer: Physical and metaphysical aspects of social support. Mental Health, Religion \& Culture. 2008; 11:23-38.10.1080/13674670701475053

Ladd KL, Spilka B. Inward, outward, and upward: Cognitive aspects of prayer. Journal for the Scientific Study of Religion. 2002; 41:475-484.10.1111/1468-5906.00131

Ladd KL, Spilka B. Inward, outward, upward prayer: Scale reliability and validation. Journal for the Scientific Study of Religion. 2006; 45:233-251.10.1111/j.1468-5906.2006.00303.x

Laird SP, Snyder CR, Rapoff MA, Green S. Measuring private prayer: Development, validation, and clinical application of the multidimensional prayer inventory. International Journal for the Psychology of Religion. 2004; 14:251-272.10.1207/s15327582ijpr1404_2

Lambert NM, Fincham FD, Braithwaite SR, Graham SM, Beach SRH. Can prayer increase gratitude? Psychology of Religion and Spirituality. 2009; 1:139-149.10.1037/a0016731

Lambert NM, Fincham FD, Stillman TF, Graham SM, Beach SRH. Motivating change in relationships: Can prayer increase forgiveness? Psychological Science. 2010; 21:126132.10.1177/0956797609355634 [PubMed: 20424033]

Levine EG, Aviv C, Yoo G, Ewing C, Au A. The benefits of prayer on mood and well-being of breast cancer survivors. Supportive Care in Cancer. 2009; 17:295-306.10.1007/s00520-008-0482-5 [PubMed: 18633651]

Masters KS, Spielmans GI. Prayer and health: Review, meta-analysis, and research agenda. Journal of Behavioral Medicine. 2007; 30:329-338.10.1007/s10865-007-9106-7 [PubMed: 17487575]

Masters KS, Spielmans GI, Goodson JT. Are there demonstrable effects of distant intercessory prayer? A meta-analytic review. Annals of Behavioral Medicine. 2006; 32:21-26.10.1207/ s15324796abm3201_3 [PubMed: 16827626]

McCullough ME. Forgiveness as human strength: Theory, measurement, and links to well-being. Journal of Social and Clinical Psychology. 2000; 19:43-55. 
McCullough ME, Emmons RA, Tsang J. The grateful disposition: A conceptual and empirical topography. Journal of Personality and Social Psychology. 2002; 82:112127.10.1037/0022-3514.82.1.112 [PubMed: 11811629]

McCullough, ME.; Larson, DB. Prayer. In: Miller, WR., editor. Integrating spirituality into treatment: Resources for practitioners. Washington, DC: American Psychological Association; 1999. p. 85-110.

Meraviglia MG. Prayer in people with cancer. Cancer Nursing. 2002; 25:326331.10.1097/00002820-200208000-00010 [PubMed: 12181502]

Mor N, Winquist J. Self-focused attention and negative affect: A meta-analysis. Psychological Bulletin. 2002; 128:638-662.10.1037/0033-2909.128.4.638 [PubMed: 12081086]

Nolen-Hoeksema S. Responses to depression and their effects on the duration of depressive episodes. Journal of Abnormal Psychology. 1991; 100:569-582.10.1037/0021-843X.100.4.569 [PubMed: 1757671]

Nolen-Hoeksema S, Wisco BE, Lyubomirsky S. Rethinking rumination. Perspectives on Psychological Science. 2008; 3:400-424.10.1111/j.1745-6924.2008.00088.x

Norris, RL.; Pérez, JE.; Canenguez, K. From cancer to caring: Survivors experience well - being through positive reappraisal and giving back within a religious community; Poster session presented at the American Psychological Association Division 36 mid-year conference on religion and spirituality; Columbia, MD. 2009.

O'Laoire S. An experimental study of the effects of distant, intercessory prayer on self-esteem, anxiety, and depression. Alternative Therapies in Health and Medicine. 1997; 3:38-53. [PubMed: 9375429]

Onitilo AA, Nietert PJ, Egede LE. Effect of depression on all-cause mortality in adults with cancer and differential effects by cancer site. General Hospital Psychiatry. 2006; 28:396-402.10.1016/ j.genhosppsych.2006.05.006 [PubMed: 16950374]

Pargament KI. The bitter and the sweet: An evaluation of the costs and benefits of religiousness. Psychological Inquiry. 2002; 13:168-181.10.1207/S15327965PLI1303_02

Pérez JE, Chartier M, Koopman C, Vosvick M, Gore-Felton C, Spiegel D. Spiritual striving, acceptance coping, and depressive symptoms among adults living with HIV/AIDS. Journal of Health Psychology. 2009a; 14:88-97.10.1177/1359105308097949 [PubMed: 19129341]

Pérez JE, Little TD, Henrich CC. Spirituality and depressive symptoms in a school-based sample of adolescents: A longitudinal examination of mediated and moderated effects. Journal of Adolescent Health. 2009b; 44:380-386.10.1016/j.jadohealth.2008.08.022 [PubMed: 19306797]

Poloma MM, Pendleton BF. Exploring types of prayer and quality of life: A research note. Review of Religious Research. 1989; 31:46-53.

Poloma MM, Pendleton BF. The effects of prayer and prayer experiences on measures of general wellbeing. Journal of Psychology and Theology. 1991; 19:71-83.

Radloff LS. The CES-D scale: A self-report depression scale for research in the general population. Applied Psychological Measurement. 1977; 1:385-401.10.1177/014662167700100306

Rood L, Roelofs J, Bögels SM, Nolen-Hoeksema S, Schouten E. The influence of emotion-focused rumination and distraction on depressive symptoms in non-clinical youth: A meta-analytic review. Clinical Psychology Review. 2009; 29:607-616.10.1016/j.cpr.2009.07.001 [PubMed: 19682781]

Ross LE, Hall IJ, Fairley IJ, Taylor YJ, Howard DL. Prayer and self-reported health among cancer survivors in the United States, National Health Interview Survey, 2002. Journal of Alternative and Complementary Medicine. 2008; 14:931-938.10.1089/acm.2007.0788

Satin JR, Linden W, Phillips MJ. Depression as a predictor of disease progression and mortality in cancer patients. Cancer. 2009; 115:5349-5361.10.1002/cncr.24561 [PubMed: 19753617]

Schwarzer F, Dunkel-Schetter C, Kemeny M. The multidimensional nature of received social support in gay men at risk of HIV infection and AIDS. American Journal of Community Psychology. 1994; 22:319-339.10.1007/BF02506869 [PubMed: 7879745]

Seeman TE, Dubin LF, Seeman M. Religiosity/spirituality and health: A critical review of the evidence for biological pathways. American Psychologist. 2003; 58:53-63.10.1037/0003-066X. 58.1.53 [PubMed: 12674818] 
Smith TB, McCullough ME, Poll J. Religiousness and depression: Evidence for a main effect and the moderating influence of stressful life events. Psychological Bulletin. 2003; 129:614636.10.1037/0033-2909.129.4.614 [PubMed: 12848223]

Strawbridge WJ, Cohen RD, Shema SJ, Kaplan GA. Frequent attendance at religious services and mortality over 28 years. American Journal of Public Health. 1997; 87:957-961.10.2105/AJPH. 87.6.957 [PubMed: 9224176]

Tabachnick, BG.; Fidell, LS. Using multivariate statistics. 5. Boston, MA: Pearson Education, Inc; 2007.

Taylor EJ, Outlaw FH. Use of prayer among persons with cancer. Holistic Nursing Practice. 2002; 16:46-60. [PubMed: 11913227]

Taylor EJ, Outlaw FH, Bernardo TR, Roy A. Spiritual conflicts associated with praying about cancer. Psycho-Oncology. 1999; 8:386-394.10.1002/(SICI)1099-1611(199909/10)8::5<386:AIDPON407>3.0.CO;2-C [PubMed: 10559798]

Toussaint L, Friedman P. Forgiveness, gratitude, and well-being: The mediating role of affect and beliefs. Journal of Happiness Studies. 2009; 10:635-654.10.1007/s10902-008-9111-8

Treynor W, Gonzalez R, Nolen-Hoeksema S. Rumination reconsidered: A psychometric analysis. Cognitive Therapy and Research. 2003; 27:247-259.10.1023/A:1023910315561

van't Spijker A, Trijsburg RW, Duivenvoorden HJ. Psychological sequelae of cancer diagnosis: A meta-analytical review of 58 studies after 1980. Psychosomatic Medicine. 1997; 59:280-293. [PubMed: 9178339]

Watkins PC, Woodward K, Stone T, Kolts RL. Gratitude and happiness: Development of a measure of gratitude and relationships with subjective well-being. Social Behavior and Personality. 2003; 31:431-452.10.2224/sbp.2003.31.5.431

Weisman AD, Worden JW. The existential plight of cancer: Significance of the first 100 days. International Journal of Psychiatry in Medicine. 1976-1977; 7:1-15.10.2190/UQ2GUGV1-3PPC-6387 [PubMed: 1052080]

Whittington BL, Sher SJ. Prayer and subjective well-being: An examination of six different types of prayer. International Journal for the Psychology of Religion. 2010; 20:5968.10.1080/10508610903146316

Wood AM, Froh JJ, Geraghty AWA. Gratitude and well-being: A review and theoretical integration. Clinical Psychology Review. 2010; 30:890-905.10.1016/j.cpr.2010.03.005 [PubMed: 20451313]

Wood AM, Joseph S, Maltby J. Gratitude predicts psychological well-being above the Big Five facets. Personality and Individual Differences. 2009; 46:443-447.10.1016/j.paid.2008.11.012 


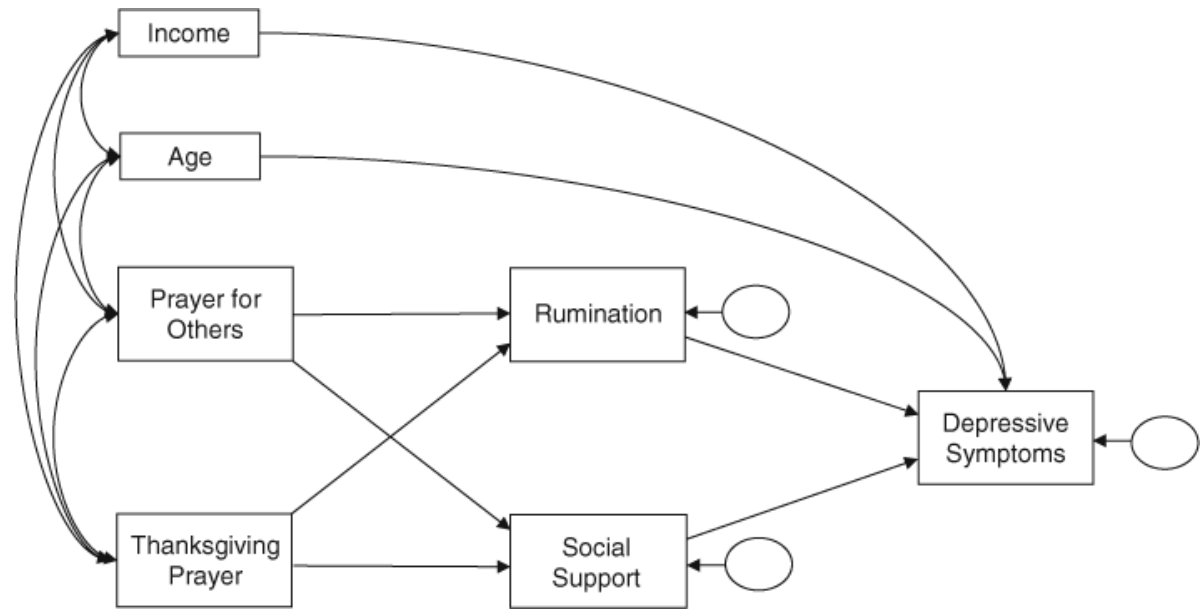

Fig. 1.

Hypothesized model of prayer types and depressive symptoms. Note: Cancer severity indices (i.e., cancer stage and months since diagnosis), gender, race, and education were not significantly associated with any of the endogenous variables. Therefore, they were not included in the model. Direct paths are designated by single-headed arrows. Correlations are designated by double-headed arrows. Error variance in the endogenous variables is represented by small circles 


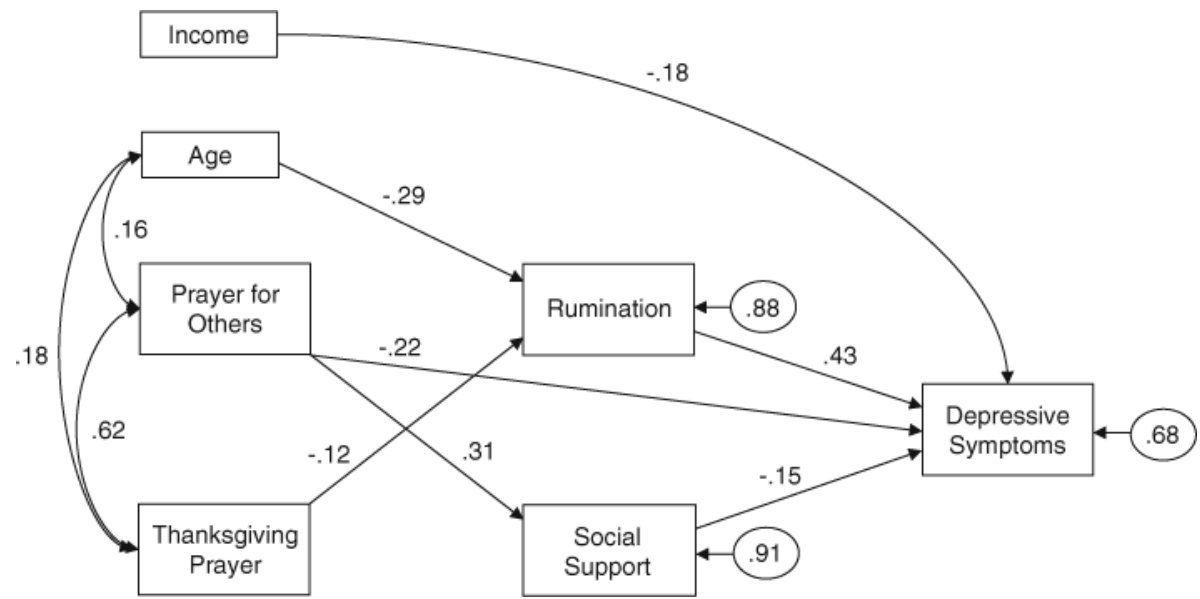

Fig. 2.

Final model of prayer types and depressive symptoms. Note: All final path coefficients were significant $(p<.05)$ 


\section{Table 1}

Demographic characteristics of the sample $(N=179)$

\begin{tabular}{|c|c|c|}
\hline Variable & $n$ & Mean or percent ${ }^{a}$ \\
\hline Age & 176 & 54.2 \\
\hline Years of education & 179 & 16.2 \\
\hline \multicolumn{3}{|l|}{ Sex } \\
\hline Female & 130 & $72.6 \%$ \\
\hline Male & 49 & $27.4 \%$ \\
\hline \multicolumn{3}{|l|}{ Race/Ethnicity } \\
\hline Alaskan Native/Native American & 1 & $0.6 \%$ \\
\hline Asian/Asian American/Pacific Islander & 2 & $1.1 \%$ \\
\hline Black or African American & 4 & $2.2 \%$ \\
\hline Latino/Hispanic & 2 & $1.1 \%$ \\
\hline White or European American & 168 & $93.9 \%$ \\
\hline Multiracial & 2 & $1.1 \%$ \\
\hline \multicolumn{3}{|l|}{ Marital status } \\
\hline Married/Living as married & 121 & $68.4 \%$ \\
\hline Single/Never married & 22 & $12.4 \%$ \\
\hline Divorced/Separated & 28 & $15.8 \%$ \\
\hline Widowed & 6 & $3.4 \%$ \\
\hline \multicolumn{3}{|l|}{ Religious affiliation } \\
\hline Christian-Catholic & 73 & $41.2 \%$ \\
\hline Christian—Protestant & 54 & $30.5 \%$ \\
\hline Christian-Non-denominational & 18 & $10.2 \%$ \\
\hline Jewish & 9 & $5.1 \%$ \\
\hline Other & 9 & $5.1 \%$ \\
\hline No Affiliation/Agnostic/Atheist & 14 & $7.9 \%$ \\
\hline \multicolumn{3}{|l|}{ Household income } \\
\hline Less than $\$ 25,000$ & 17 & $10.6 \%$ \\
\hline$\$ 25,000-\$ 49,999$ & 30 & $18.8 \%$ \\
\hline$\$ 50,000-\$ 74,999$ & 41 & $25.6 \%$ \\
\hline$\$ 75,000-\$ 99,999$ & 20 & $12.5 \%$ \\
\hline$\$ 100,000$ and above & 52 & $32.5 \%$ \\
\hline \multicolumn{3}{|l|}{ Work status } \\
\hline Full time & 39 & $22.2 \%$ \\
\hline Part time & 26 & $14.8 \%$ \\
\hline Medical leave & 36 & $20.5 \%$ \\
\hline Homemaker & 11 & $6.3 \%$ \\
\hline Unemployed/Looking for work & 10 & $5.7 \%$ \\
\hline Retired & 54 & $30.7 \%$ \\
\hline \multicolumn{3}{|l|}{ Type of cancer } \\
\hline Breast & 51 & $29.1 \%$ \\
\hline
\end{tabular}

J Behav Med. Author manuscript; available in PMC 2014 October 02. 


\begin{tabular}{lrl}
\hline Variable & $\boldsymbol{n}$ & Mean or percent \\
\hline Gastrointestinal & 26 & $14.9 \%$ \\
Blood and lymphatic & 23 & $13.1 \%$ \\
Lung & 20 & $11.4 \%$ \\
Gynecologic & 18 & $10.3 \%$ \\
Head and neck & 10 & $5.7 \%$ \\
Brain & 9 & $5.1 \%$ \\
Prostate & 5 & $2.9 \%$ \\
Skin, muscle, and bone & 5 & $2.9 \%$ \\
Other & 5 & $2.9 \%$ \\
Multiple & 3 & $1.7 \%$ \\
Stage of cancer & & \\
II & 26 & $15.2 \%$ \\
III & 39 & $22.8 \%$ \\
IV & 78 & $45.6 \%$ \\
Non-staged & 28 & $16.4 \%$ \\
\hline
\end{tabular}

${ }^{a}$ Percent is based on valid (non-missing) answers 


\title{
Table 2
}

\section{Additional prayer items}

\author{
Prayer for one's health $(a=.92)$ \\ I asked God to make me healthy. \\ I prayed for God to cure me of my cancer. \\ Prayer for emotional strength $(a=.89)$ \\ I asked God for the strength to deal with my cancer. \\ I prayed for help to endure my cancer. \\ Prayer for the well-being of others $(a=.96)$ \\ I prayed for the well-being of others. \\ I prayed for the welfare of other people.
}




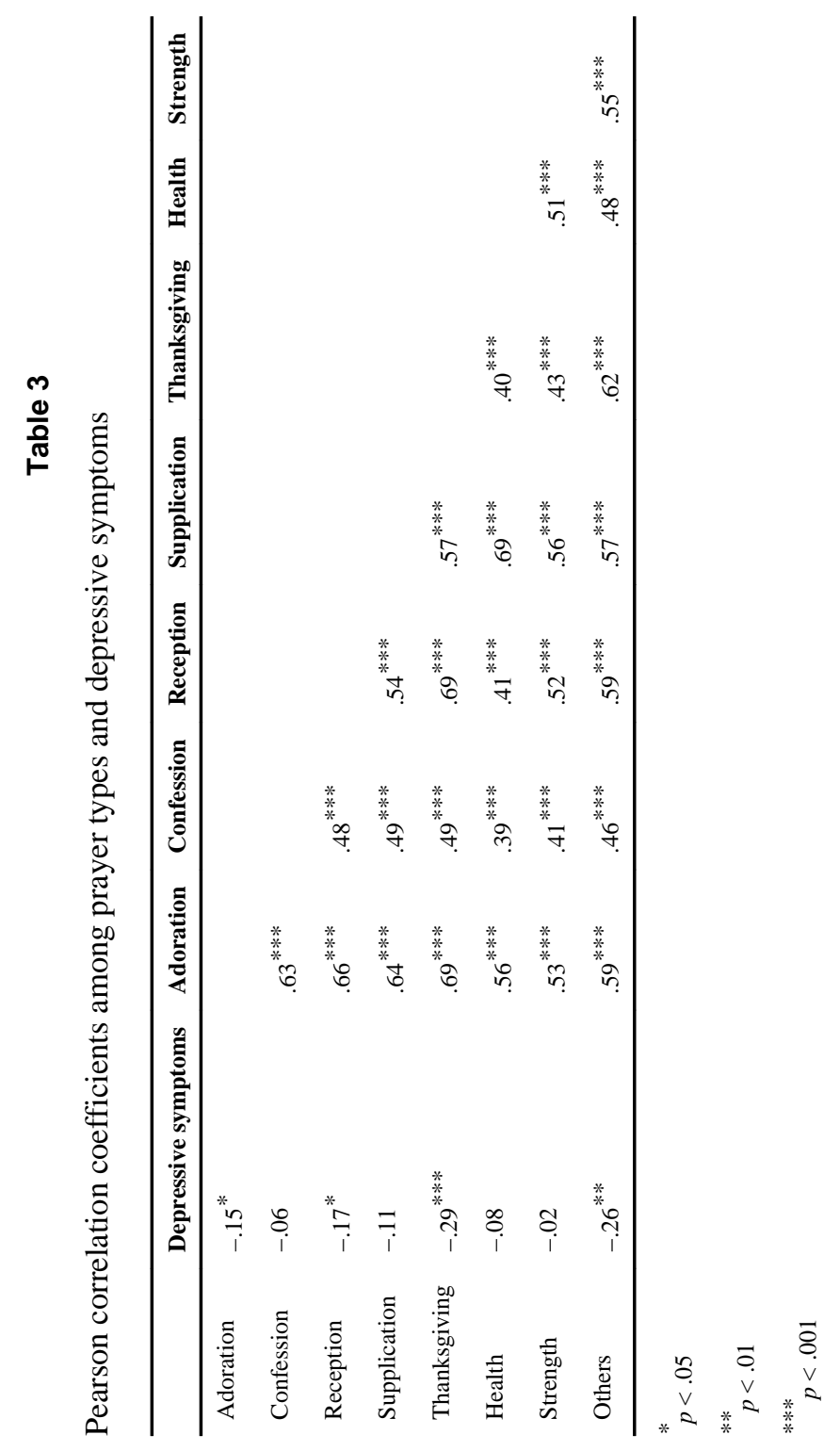

J Behav Med. Author manuscript; available in PMC 2014 October 02. 


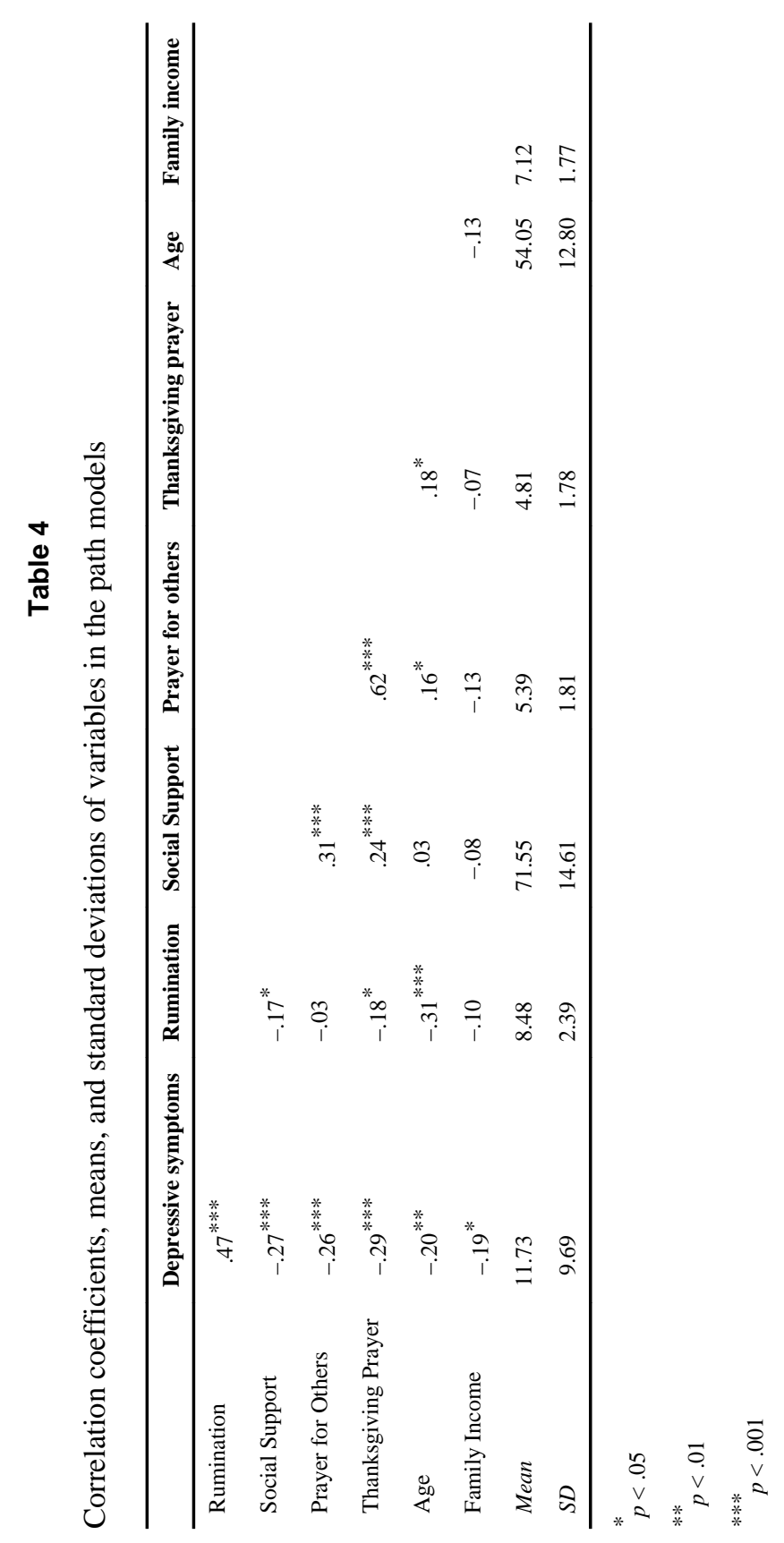

